\title{
The Research and Development on Shoulder Beam of CFST
}

\author{
LAN Tao $^{1,2, \mathrm{a} *}$, HU Weizhong ${ }^{1, \mathrm{~b}}$, GAO Ruixiang ${ }^{3, \mathrm{c}}$ and WANG Yu ${ }^{2, \mathrm{~d}}$ \\ ${ }^{1} \mathrm{Xi}$ ' an University of Architecture and Technology, China \\ ${ }^{2}$ CSIC Architecture Design and Research Institute Co. Ltd, China \\ ${ }^{3}$ Taiyuan University of Science and Technology, China \\ aqd_lantao@163.com, bhwz_2016@163.com, ${ }^{\mathrm{a}} 921302083 @ q q . c o m,{ }^{\mathrm{d}}$ wangyu_7307@126.com
}

\begin{abstract}
This paper elaborates the research on mechanical behavior of shoulder beam joint of CFST column in China based on the experimental research, finite element analysis and theoretical calculation. Besides, this paper summarizes and analyses the design approaches of shoulder beam joint of CFST column, which is instructive for the further related studies and applications. Finally, this paper presents some existing problems which occurred in current researches on shoulder beam joint of CFST column.
\end{abstract}

\section{Introduction}

Shoulder beam of CFST column has been extensively used in the design of large industrial plants for two decades in China. In shoulder beam of CFST column, the lower column is made of CFST lattice column and the solid-web section is adopted in the upper column. Shoulder beam of CFST column can be divided into traditional shoulder beam and improved shoulder beam in accordance with the structures: the lower CFST column of the traditional shoulder beam extends to the top of the shoulder beam; the elevation of the lower CFST column of the improved shoulder beam is reduced to the bottom flange of shoulder beam.

\section{Research Status of Mechanical Behavior}

So far a few scholars in China have conducted the research on bearing behavior of shoulder beam of CFST column. Therefore, there are three essential research methods: experimental research, finite element analysis and theoretical calculation.

Experimental Research. At present, experimental research is limited to the static test for the shoulder beam of CFST column, and the research mainly focus on the mechanical behavior of the shoulder beam joint.

Traditional shoulder beam. The single-web shoulder beam with double columns. The analysis of shoulder-beam stress distribution had been made by Yu Anlin of Xi'an University

*Corresponding author: qd_lantao@163.com 
of Architecture \& Technology [1]. Given the initial bending of the web and eccentric load, the analysis results cannot correspond with the finite element analysis results of literature [2]. Xue Ying of Yanshan University did the research for two kinds of 1:2 reduced scale models of side-column shoulder beam [3]: one is upper column's outer-flange tangent with downer CFST column; the other is upper column's outer-flange intercross with downer CFST column. The study results show that the tangent-type shoulder beam is better than the intercross-type shoulder beam in mechanical behavior.

The double-web shoulder beam with four columns. Yu Anlin of Xi'an University of Architecture \& Technology conducted a test for a single diagonal lacing of shoulder beam[4] and a herringbone lacing of shoulder beam[5], by using the loading method with the load ratio of about 1:2:1.5. The mechanical behavior of the short shoulder beam is similar to that of the shoulder beam of literature [1]. The Literature [4] indicates that the axial stress of shoulder-beam lower column is distributed according to the relative stiffness ratio of both steel tube and concrete, and it suggests that bending normal stress of shoulder-beam cross section should be calculated by the effective section method. The literature [5] states that herringbone lacing makes a similar elastic support to the middle section of the shoulder beam; however, the premature buckling of shoulder beam web will occur because that the bearing capacity of herringbone lacing is about $20 \%$ higher than that of the single diagonal lacing. Besides, the test for three kinds of 1:3 reduced scale models of shoulder beam with the reinforced two-way slab crossing the column [6] was carried out by Han Changbiao and his colleges in Suzhou University of Science and Technology. In this test, upper and lower columns are both lattice column of CFST with four main elements, and the web thickness or the ribbed stiffener arrangement are changed. The results display that the web thickness of shoulder beam has a great influence on the bearing capacity of shoulder beam joint.

Improved shoulder beam. The single-web shoulder beam with double column. Su Ming-zhou, Dong Zhen-ping and Wang Ya-jun of Xi'an University of Architecture \& Technology conducted an experimental study on four kinds of 1:3 reduced scale models of shoulder beam [7-9] including two side columns and two middle columns of shoulder beam. The experimental results show that there are some differences in mechanical behavior between side columns and middle columns. Wang Li-hu and his colleges of Anhui Institute of Architecture \&Industry has monitored the stress change of shoulder beam in its application by using vibrating wire sensor [10].

The double-web shoulder beam with double column. Dong Zhengping [8] and Wang Junfeng [11] made the experimental study on four kinds of 1:3 reduced scale models of shoulder beam including two side columns and two middle columns of shoulder beam. The results indicate that the bearing capacity of double-web shoulder beam is higher than that of the single-web shoulder beam; shear stress is control of shoulder beam, however, bearing capacity of the first tilted belly poles should be considered in this design since the fracture and weld crack of lower column tilted belly poles occur when the bearing capacity is close to ultimate load. The buckling of double webs occurs in the different time and the deformation of them is not identical; the shear lag has a major effect on the upper flange.

Finite Element Analysis. The finite element software Ansys is one of universal research methods for the mechanical behavior analysis of shoulder beam joints of CFST column. This method could make up for the disadvantage of the experiment research and provide reference data for the research. Therefore, a number of joint mechanical behavior analyses are feasible with little limitation of finite element analysis.

Traditional shoulder beam. The single-web shoulder beam with double columns. Jin Tiande of Hang Zhou Urban Construction Design Institute and Rao Zhiying of Zhejiang University made the elastic finite element analysis [2] on three kinds of shoulder beam, which emphasize the stress distribution of the shoulder beam joint. Xiping, the professor of 
Anhui University of Architecture, made a research on side column [12]. Yang Chengchen in Wuhan University of Technology and his colleges proposed that clamped beam should be adopted in the stress distribution of shoulder beam in accordance with the research on the joints of shoulder beam with the exterior stiffener ring [13].

The double-web shoulder beam with four columns. Wang Yi in Tongji University and Xia Hanqiang in Shanghai Research and Design Institute of Mechanical and Electrical made anlysis on stress distribution of shoulder beam by using three types of finite element models[14], including linear pure steel model, linear steel-concrete common work model and steel-concrete contact force model, in order to verify the security of shoulder beam joint. Then Wang Yi compared the results between finite element analysis simulation and the simplified stress calculation of plates and weld beads of shoulder beam joints [15]. It is found that the analysis result of reinforced two-way web plate crossing the column by Han Changbiao who adopted finite element method almost coincides with the result of the experimental tests. Hence, the research on the effect of web thickness and ribbed stiffener distribution on the shoulder-beam bearing capacity is conducted [6].

Improved shoulder beam. The single-web shoulder beam with double columns. The literature [3] focuses on the research of two side-column shoulder beams: one is upper column's outer-flange tangent with downer CFST column; another is upper column's outer-flange intercross with downer CFST column. The result indicates that two hysteresis curves for both shoulder beam joints are full and skeleton displacement curves of both shoulder beams have a long reinforcement section when they reach the peak value. This research also analyzes the stress distribution of column limb and effect of web thickness on bearing capacity. In the literature [10], there is a comparison between the finite element analysis result and the actual data. The results shows that there is a difference in judgment for the stress state of top flange plate without considering the upper column load and bond slip between steel tub and concrete. Liu Zhifeng[16] and Zhao Feng[17] in Xi'an University of Architecture \& Technology employed the verified finite element model to analyze the mechanical behavior of typical shoulder beam and their parameters based on representative specimen. The finite element analysis result in literature [8] [9] coincides with the result of experiment for middle-column shoulder beam, but differs from the result of side-column shoulder beam. This is probably caused by partially rigid-body displacement of foundation beam.

The double-web shoulder beam with double columns. The result of finite element analysis by literature [8][11] provides a proper match with the experiment result. In addition, the literature [8] makes an analysis on the parameters by changing the web thickness and height-span ratio based on the typical conditions. The result of parameter analysis in literature [8] and the parameter analysis result of Single-web shoulder-beam in the literature [17] may complement each other.

Theoretical Calculation. Shen Zuyan, a professor of Tongji University, put forward a calculation formula on rotational stiffness of shoulder beam by using spring hinge instead of shoulder beam [18]. Liu Zhicai in Jiangsu Huaxia Real Estate Development Company Limited and Dui Guansuo in Nanjing University of Science And Technology made a research on the shoulder beam which is simplified to an elastic hinge with angle stiffness. Then, they presented the respectively transcendental equations on the critical loads of shoulder beam under the connection between shoulder beam and roof truss through the hinged way and rigid connected way [19]. It is known that the different connection ways have an influence on the stability of column. The literature [8] focuses on the influence of shoulder beam stiffness on mechanical behavior of industrial plants frames by theoretical analysis and example checking computation. The result indicates that the stiffness of 
shoulder beam has a minimal impact on the column when the high-span ratio is higher than 4.0 and the linear stiffness ratio of shoulder beam to upper column is higher than 1.0.

\section{Design Method}

At present, the design approach of shoulder beam joint of CFST column is the same with that of section steel column shoulder joint. The current design approaches are compared in the literature [7-12] [17]. Then, the result displays that the calculation method recommended by Design Manual of Steel Structure is too conservative and can be used to calculate any shoulder beam. However, the calculation methods recommended by Design Manual of Construction and Steel Structure and Design and Calculation Manual of Steel Structure are not reliable. Especially, there are differences in the calculation method from Design Manual of Construction and Steel Structure.

Based on the literatures [1] [4] [5], Yu Anlin raises the proper design method of shoulder beam (the partial flange is considered) and a way to calculate the strength of steel tube in the field of joints [20]. Bending normal stress of shoulder beam of CFST column is calculated in terms of effective section. This is the method: $a$. all section of web is effective; $b$. the formula of the effective width of upper and lower flange: $b_{e}=0.36 L^{\prime} \ll 20 t$. The shoulder beam is calculated by the following equation:

$$
\begin{aligned}
& \text { bending normal stress } e=\frac{M}{W} \ll f \\
& \text { shear stress } f=\frac{1 \cdot 1 Q}{h_{w} t_{w}} \ll f_{v} \cdot T \cdot U \\
& \text { equivalent stress } \sqrt{e_{1}^{2}+f_{1}^{2}} \ll 1.1 f
\end{aligned}
$$

The literature [9] uses the methods from Design Manual of Construction and Steel Structure and Design and Calculation Manual of Steel Structure to calculate a improved single-web shoulder beam joint with double column, but the width of flange is calculated in terms of the effective section formula of the literature[20]. The result shows that the yield load is still $35.8 \%$ higher than the experimental value. The literature[8] also makes use of this method to calculate the improved single web shoulder beam joint with single column. The calculative result is similar to the experimental values. However, the calculative result is greater than the experimental values. It is considered that the calculation method is not suitable for the calculation of double -wed shoulder beam. The literature [17] proposes a practical formula to caculate the single-web shoulder columns:

$$
V_{\text {max }} \ll V_{u}=0.3 t_{w} h_{w} f_{y}\left(\frac{h_{w}}{L_{2}}{ }^{3} 0.45\right)
$$

Then, the literature[17] verifies the rationality of the formula by comparing with the results of finite element analysis. However, the literature[8] states that the formula does not take into account the height-span ratio and then puts forward a practical formula of single-web of shoulder beam:

$$
t=k \cdot \frac{1.15 a V_{\max }}{h_{w} t_{w}} \ll f_{v}
$$


The literature[11] suggestes that an uneven force coefficients 0.6 should be introduced to calculate the double-web shoulder beam in terms of the average shear stress formula in Design Manual of Construction and Steel, namely:

$$
t=\frac{0.6 V_{\max }}{h_{w} t_{w}} \ll f_{v}
$$

Compared with the experimental data, the calculatuion is proved reasonable. But the calculative result of literature[8] by using the method are out of line with the experimental data. Given the characteristics of the stress mode of double web and single web, height-span ratio, stress characteristics, spatial configuration and so on, the literature[8] puts forward a practical formula of shoulder beam strength:

$$
t=m \cdot n \cdot k \frac{a V_{\max }}{h_{w} t_{w}} \ll f_{v}
$$

We could use the formula to calculate the stress of single-web shoulder beam and double-web shoulder beam.

\section{Conclusion}

At present, these researches concentrate on the specific construction but they are lack of coherence and system. These studies focus on mechanical behavior of the shoulder beam of CFST column but they are not thorough in bearing mechanism and design method. Besides, theoretical research on the shoulder beam of CFST column is also insufficient and theoretical research of new structural form fall behind compared with its application. Study on mechanical behavior of shoulder beam of CFST column under the action of dynamic load is infrequent. Bond slip between steel tube and concrete is not considered in the finite element analysis. Therefore, it is necessary to further improve the research in the future. The calculation theory and simple and practical calculation method of shoulder beam joint should be established. Currently, the calculation method with partial flange in feasible, but the evaluation of flange effective width remains to be explored in the future.

\section{References}

1. Yu Anlin, Tong Gen-shu, Test Study And Theory Analysis on the Single Web Stay Member of Open CFST with Two Main Elements, J. Industrial Construction, 28 (1998).

2. Jin Tiande, Rao Zhi-ying, Stress Analysis on Shoulder Beam of Open Concrete Filled Steel Tube, J. Zhejiang Building, 5 (1997).

3. Xue Ying, Theorerical Analysis and Experimental Study on CFST Shoulder Beam Joint, D. Yanshan University, 2008.

4. Yu Anlin, Tong Gen-shu, On Bearing Behaviors of Single Diagonal Lacing Double Web Stay Member of Open Concrete Filled Steel Tube With Four Main Elements, J. Journal of Xi'an Highway University, 1998.

5. Yu Anlin, Tong Genshu, Carrying Behaviors of Herringbone Lacing Double Web Stay Member of Open Concrete Filled Steel Tube With Four Main Elements, J. Journal of Xi'an University of Architecture \& Technology(Natural Science Edition), 30(1998)112-114.

6. Han Chang-biao, Key Technologies of Single-Layer Super-Storey Large Cross-Overloaded Industrial Building Structure System, D. Suzhou University of Science and Technology, 2012. 
7. Su Ming-zhou, Experimental Study on the Bearing Capacity of Improved Single-Web Shoulder Beam Member with Double Concrete-Filled Steel Tube Column, J. Journal of Xi' an University of Architecture \& Technology(Natural Science Edition), 42(2010).

8. Dong Zhenping, Study on Performance and Design Method of CFST Column's Shoulder Beam, D. Xi'an University of Architecture \& Technology, 2011.

9. Wang Yajun,Test Study on Improved Type of Single Web Shoulder Beam Joint of Concrete Filled Steel Tube Column, D. Xi'an University of Architecture \& Technology, 2009.

10. Wang Lihu, Study on the Mechanical Behaviors of Side Column Single-Web Shoulder Beam with Two CFST Columns, D. Anhui institute of Architecture \&industry, 2012.

11. Wang Junfeng, Experimental Study on Bearing Capacity of Double-Web Shoulder Beam Member with CFST Columns, D. Xi' an University of Architecture \& Technology, 2009.

12. He Xiping, Mechanical Properties Analysis of Single-Web Shoulder Beam in Side Column of Double Steel Tube-Confined Concrete Columns, J. Journal of Anhui Institute of Archi-tecture \& Industry(Natural Science), 2013.

13. Yang Chengchen, Study on Behavior of CFST Column with Outer Ring Stiffeners, D. Wuhan University of Technology, 2007.

14. Wang Yi, Xia Hanqiang, Wang feng, Finite Element Analysis on Shoulder Beam of CFST With Four Main Elements in The Heavy Industrial Plant, C. The fourth strait and Hongkong steel structure technical exchange meeting, 2006.

15. Wang Feng, The Design and Research on Shoulder Beam Member of Concrete Filled Steel Tube Laced Columns in the Heavy-Duty Workshop, J. Construction \& Design for Project, 2011.

16. Liu Zhifeng, Study on the Mechanical Behaviors of New Type Single-Web Shoulder Beam with Two CFST Columns, D. Xi'an University of Architecture \& Technology, 2008.

17. Zhao Feng, Mechanical Behaviors and Design Method Study of New Type Single-Web Shoulder Beam Member with CFST Columns, D. Xi'an University of Architecture \& Technology, 2009.

18. Shen Zhuyan, Zheng Yi, Analysis of the Stiffness of Shoulder Beams, J. Building Structure, 29(1999) 50-52.

19. Liu Zhicai, Dui Guan suo, The Stability on the Polystyle Columns with Shoulder Beams, J. Journal Of Nanjing University Of Science \& Technology, 2001.

20. Yu Anlin, Tong Genshu, Study Conclusion and Design Proposal on Stay Member of CFST, J. Journal of Xi' an University of Architecture \& Technology, 30(1998) 247-249. 